\title{
The "Filtering" Concept: Blended Learning Culture in Architectural Education
}

\author{
Bengi Yurtsever, Çiğdem Polatoğlu \\ Y1ldız Technical University, Istanbul, Turkey
}

\begin{abstract}
The study aims to discuss how the learning problematic and the relation between learning and perception should be interpreted in the process of architectural education. The issues like "individual, experience, perception, and image" will have been handled related with the concept of "filtering," while the problems are being discussed on the question of "How the environment impacts on human and what level is it." Learning can be defined as a process of comprehension which should be collected by an individual with so many different components. Subjects' way of thinking or seeing is seen very important at this process. At these stages, there is an intense production which has emerged with blended "new" and "old." Individual and his/her own components play a leading role at the movement that between being "new" and "old." These components are not static. They can be changed according to daily life, environment, and individuals. Therefore, it can be seen as a far expectation for the original aim of learning, which comprehending any focus issue in the same way or style by listeners. In this context, a case study has been interpreted between these concepts at the end of the study.
\end{abstract}

Keywords: architectural education, filtering, blended learning, perception, experience

\section{Introduction: Perception and Experience on the Education of Architect}

The architectural design studio has got a changeable and multi-component structure that cannot be reduced to a single binder. This changeable structure has a potential force to make the environment alive. But this potential is destroyed in some situations - mostly for seeing "final" product. The most important variances of this multi-component environment are the coordinator, student and relation between them. A sharing environment where can everybody from both sides carry from their own thought to different dimensions can strengthen this relation. The filters that vary from person to person should be involved in this experience process. In this study, especially it was aimed that doing a research on why the filters can be so important to the process of architectural design studio's learning. While the process of reaching this aim, a discussion was done on the subject of "How this filters can contribute to the environment of architectural design studio where is trying to be in a harmony with today's dynamic structure?"

At the beginning, it is being intended to make a scrutinizing on the problematic of learning in the architectural education for to specify the problem. It has been tried to discuss the relation of learning with perception and how it can be addressed under the environment of architectural education. Within this scope, it is being intended to improve the study by asking questions and trying to reach their answers. Many questions,

Bengi Yurtsever, M.Sc., research assistant, Department of Architecture, Yıldız Technical University.

Çiğdem Polatoğlu, Dr., professor, Department of Architecture, Yıldız Technical University. 
such as "What can influenced perception in the architectural education process; what influences from the past on perceiving the student and the lecturers' environment;" "How do they influence the individual in terms of creativity and critical thinking;" and "Could the lecturer think of the learners' learning skills independently of these perceptions and filters" have become tools that carry the debate to different dimensions throughout the study. Factors are relevant to the case have been tried to be searched by a holistic approach, the possible types of relations among them have been tried to be supported by various resources (Yildirim \& Simsek, 2008). In the study that was intended be gathered within the pattern of circumstance study, a fact—seeming to be a current problem - has been scrutinized within its own reality (Yin, 1984). The study can be considered as a first research phases of an experimentally processes that can be spread over an extensive period. The conceptual framework for the study is based on the concept of "filtering" that Rapoport (1997) put forward. According to Rapoport (1977), the cultural and personal image is very important in reaching the perceived world within the referred filtering (see Figure 1). Even, it is a part of the process.

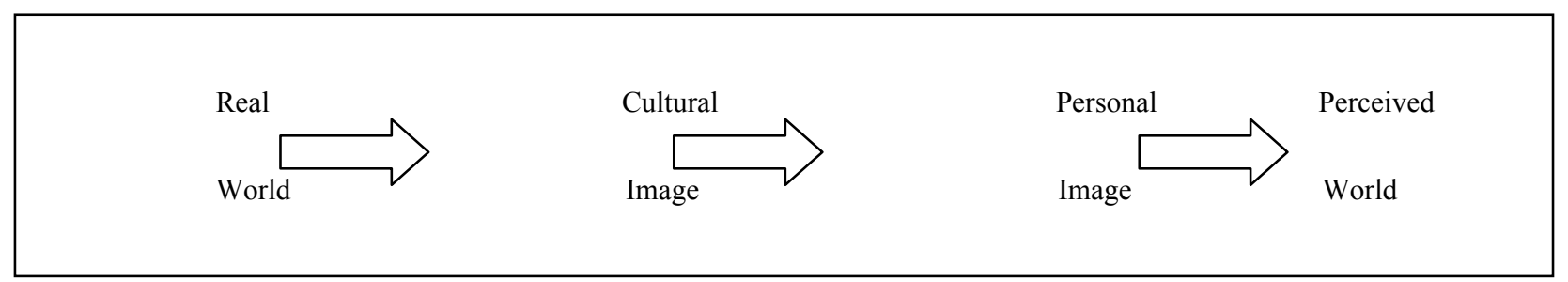

Figure 1. Cultural and personal images as filters (Source: Adapted from Rapoport, 1977 by Bengi Yurtsever, 2017).

At this point, the experience becomes an effective factor. According to John Berger (1999), thoughts or beliefs were affecting the appearance of objects. It can be said that what was believed was being seen as also benefiting from the ways of seeing referred by Berger. Seeing something in a real sense is reflected in the visualization of a different view of each other with the formation of networks established with experience. Therefore, it is necessary firstly to have an idea that everything that is seen outside is indeed a person's own point of view. In this way of seeing the individual itself, everything is connected to each other and perceived. As specified by Lynch (1996), nothing was perceived on its own. It was perceived to be related to the environment, to the chain of events that gave birth to it, and to the memories of past experiences.

The entire process in this perception is reciprocal. The perceived things belong to the person himself. But the things that the individual sees are the ones that he/she believes as specified by Berger (1999), in other words, they were the things that he/she had previously experienced. It is a new articulation of the network being established and exists by the existence of old and past. This way of seeing has a dynamic structure. The articulation process being referred is an experience and perception process that continuously expands its perimeter and in which the time of establishment of connections is uncertain. According to Polatoğlu (2012), human-environment relations were the totality of mutual interactions, and the perception of the environment took place in a complex way through various senses. This interaction is developing as the formation of perception-cognition-image. The perceived things in the interaction process form the image along with the known thing.

By benefiting from all these, it can be said that it takes a certain period of time in order that the image can be formed in the person. What is important in this case is to acquire awareness of how and in what way the environment is presented, and to internalize the acquired information in relation to the present. This period is the period, in which you have the potential to turn into a new image, establishing its connection with 
experiences and taking up space. According to the revision of Neisser (1976) made over the opinions of Gibson, as was known from data processing theories, data processing was not linear but rather cyclical (Garling \& Golledge, 1989). The individual interprets the data in his/her own way and accepts that it is able to find a position. According to this, the data deemed as "accurate" by the individual are accepted, and it is directed to research for more data. The ready data moves towards gathering more information along with the newly perceived one. And each image obtained afterwards actually has a quality that may change the next one and even the previous one as per the instance. In the presence of all these variables, reflecting this static approach to the education process by thinking the architect fixed is revealing a very conflicting process.

\section{Literature Review}

According to Polatoğlu (2012), the architect was also forming the lives of individuals who would be living there while creating an environment. The thing that the architect is trying to do is not just technically producing a building, but also providing the individual a social environment. The architecture requires thinking as a whole the contrasts, differences, and "new ones" arising from their tension. Thus, architecture also places emphasis on thinking as all the professions and as a lifestyle beyond the profession. In order to be able to think and establish new contexts depending on this, it is necessary to perceive what is present, to be perceived in a sense. According to Lang (1974), this perception was a process of obtaining or acquiring information from the environment, and as it referred before, it was a dynamic process.

On the issue of perceiving the environment, eternal simplicity is as confusing as the circumstances where everything is certain. For something, in order to be perceived and positioned in the image, it must be able to take place within a certain axis. The ability to consciously place an axis is the result of an education and learning in every sense. The management of this axis and the change of the axes should be one of the gains of the education process. Being in an undefined process will prevent the discovery of the "new" in the sense of design. In the educational process of architecture, it is primarily the duty of the lecturers to make this indefinite in itself. The lecturer must be aware of the products that can emerge from the differences and should not let a taken a fixed form the students in the name of some quantitative facilities. It should be remained within the technological possibilities of the day as much as possible, and it should be ensured for the student to see the "present time" through discussions on the day. Thus, the awareness of the student for agenda, present environment, and himself/herself should be created. In the name of gaining the sustainable interest of the student, implementations where they can find themselves, they can place themselves and they may "easily" share their sensations should be performed, and such an environment should be ensured. In implementations which are completely in space, whose position is not certain and which are completely "unknown," the student will be able to move away from the study. The reason of it is being unable to make a start by gaining a seat inside uncertainty, being unable to position himself/herself in the study, and thus, "being unable to adopt" the study. Also, it is specified that it is required to involve in the tension of accustomedness and novelty for the sustainability of the perceiving individual's interest (Lozano, 1988). Within that tension, the student will be able to gain a seat through accustomedness. And along with discovering the new one, the interest of the student on the issue will increase more.

At this point in the education of an architect, his/her power of being able to question is also gaining importance. Accepting the existing one as it is, being able to question it also by benefiting from his/her experiences should again be one of the acquisitions within the process. An applied course for providing the skill 
of critical thinking should have a content that will provide the student the skill of creative thinking, that will establish his/her relation with daily life and that will improve his/her imagination by using contemporary representation tools, and as emphasizes by Arnheim (2015), it should provide the student the skill of sight and thinking by which he/she will be able to establish the relation of abstract and concrete. Instead of providing only abstract concepts, definitions and some temporary information to the student who has just started architecture education, it should be intended to teach means of reaching information that is changing as per context.

\section{The "Filtering" Concept at the Blended Learning Process}

One of the most controversial topics is the teaching of thinking. The problem of how it can be evaluated, even if it can be taught, is being investigated in different fields of psychology to education. On this issue, Brandt (1985) alleged that teaching had three components regarding thinking: teaching cognitive processes, being conscious of thinking, and epistemic cognition (Seferoglu \& Akbiyik, 2006). Especially, the important point is being conscious of thinking and creating a kind of awareness. The student who is able to grasp and comprehend the awareness of it from a point will be able to easily make the articulations on it, and most important of all, he/she will be able to articulate by questioning. A thought infrastructure cannot be formed without providing awareness and without wondering why and how some things are made.

The beginning of the process of recognizing pieces and relating them also passes from perception. Then, the existence of an indistinguishable connection among perception-architecture-design-education can definitely be mentioned. It is important that the issue can be discussed mutually, with the issue being addressed on the axis of architectural education. Whether the communicated things are being comprehended by the students or not, or especially "how" they are being comprehended is a problem. More precisely, as also referred in the beginning of the study, it takes part in space, in an unidentified situation.

Of course, it cannot be said that each study is in space. But being unable to get feedback regarding the study is being able to cause the realization level of learning not to be understood completely. In this feedback process, it is important that the student can adopt the practice and add something to him/her. In this way, the student is able to introduce himself/herself to lecturer with feedback. In this case, it can be said that the relation in between the instructor and student, is within a continuous cycle providing mutual gains.

Along with having many learning styles being implemented and relevant educational approaches, it is being considered that some of these are now unable to meet the expected performance under today's conditions. The fact that the five senses in architecture together with an intuitive set of components are in the works can force some of these approaches. In this sense, the conditions of the day necessitate an approach in which not only the focus of the lecturer, but also the sharing cycle mentioned earlier can be achieved and the center moves between the lecturer and the student. Beyond stability, this is thought to be possible in an environment where each process is dynamic and controversial. This aforementioned environment can be achieved not by a single source but by the provision of multiple sources. A blended approach, where virtual and real environments can be used together, can bring a proposal for this problem.

Blended learning can be defined as a learning method combining the possibilities of face-to-face education and online education and using the positive aspects of both according to need (Osguthorpe \& Graham, 2003) (see Figure 2). It is thought that the learning platform can be expanded by virtual discussions or sharing within the conditions of the day, and the strict boundaries between the lecturer and the student may be lost on this 
occasion. The disappearance of these boundaries will also allow the reciprocal recognition of what is below or above the filter.

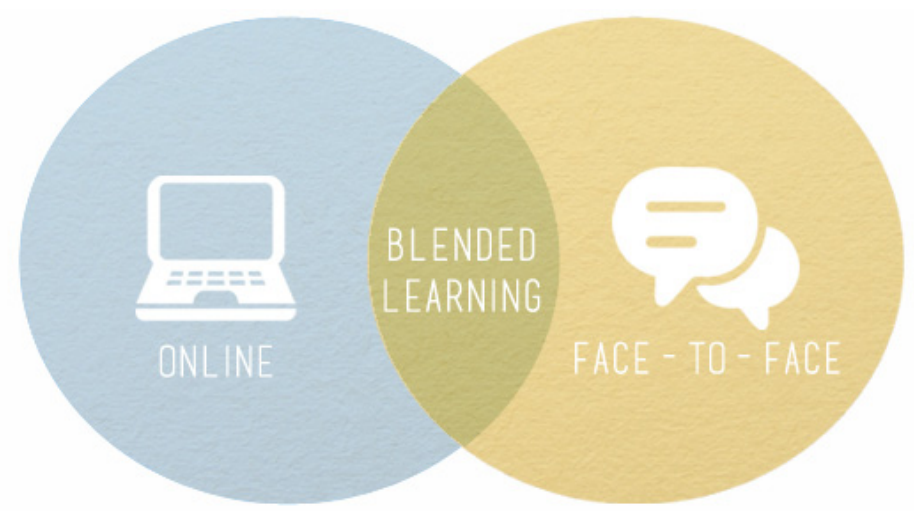

Figure 2. Blended learning.

(Source: Retrieved from http://www.careerfaqs.com.au/images/news_pages/blended-learning.jpg)

Research shows that an individual may have other learning styles besides a dominant learning style. Temel (2002) in addition to this was specifying that the individual might have different learning styles, but his/her degree of using these may differ. The basic factor in the rise of all these differences is the cultural, environmental, and social differences that the individual has and his/her personality that had formed along with these. Rapoport (1977) was specifying in his/her studies that the individual passed through a specific filtering in reaching the world he/she perceives. In general, proper learning may be defined as the student's ability to transform to an image the things he/she perceives. And during this transformation, there are two images included in the process specified by Rapoport. These function as filters and they generate the existing one again as peculiar to the individual. These are cultural and personal images.

The cultural and personal images of the student affect his/her learning. Besides what and how he/she learns, also what he/she sees is becoming different. This difference arises from different forms of perception that originate from filters. Even if it does not appear in reality, the individual sees that thing differently by taking advantage of his/her past and experience. Rapoport's filters act as a filter in perceptions of the student. According to Rapoport (1977), the "cultural images" of the student seem very important in this elimination operation. Cultural image hosts many social components as from the hometown of the student to where he/she, his/her family, and friends live. And personal images — as will be understood by its name - are images formed completely relevant to the individual himself/herself. These images are to a large extent being formed through the experiences of the students. And of course, cultural components exist in its origin. At this point, if the "How and what level the environment affects the individual?" question of Rapoport will be answered, this may be primarily expressed as "The environment enables the individual to perceive and see." In other words, all the aforementioned components are images providing the individual "how" the environment looks like. And in architecture, being able to comprehend the environment with all its components within the design process and being able to make the complete assessment of physiological, psychological, and sociological requirements of the users seem important for the originality of the production process.

In learning, teaching all these different perspectives is of course not possible. It is not possible, nor should it be, to be transmitted in the same way by a rote learning approach. However, the student should be aware of how these differences can be assessed and what may arise from mutual differences. Sorting the mentioned 
filters in a static sequence may not be a very accurate approach. Cultural-personal images are actually interwoven images. Separating them from each other or prioritizing them in a queue may limit the perspectives. The important point is the mutual awareness regarding the existence of these filters. According to this approach, these filters have a not ignorable share in a studio environment in the process of architectural education (see Figure 3).

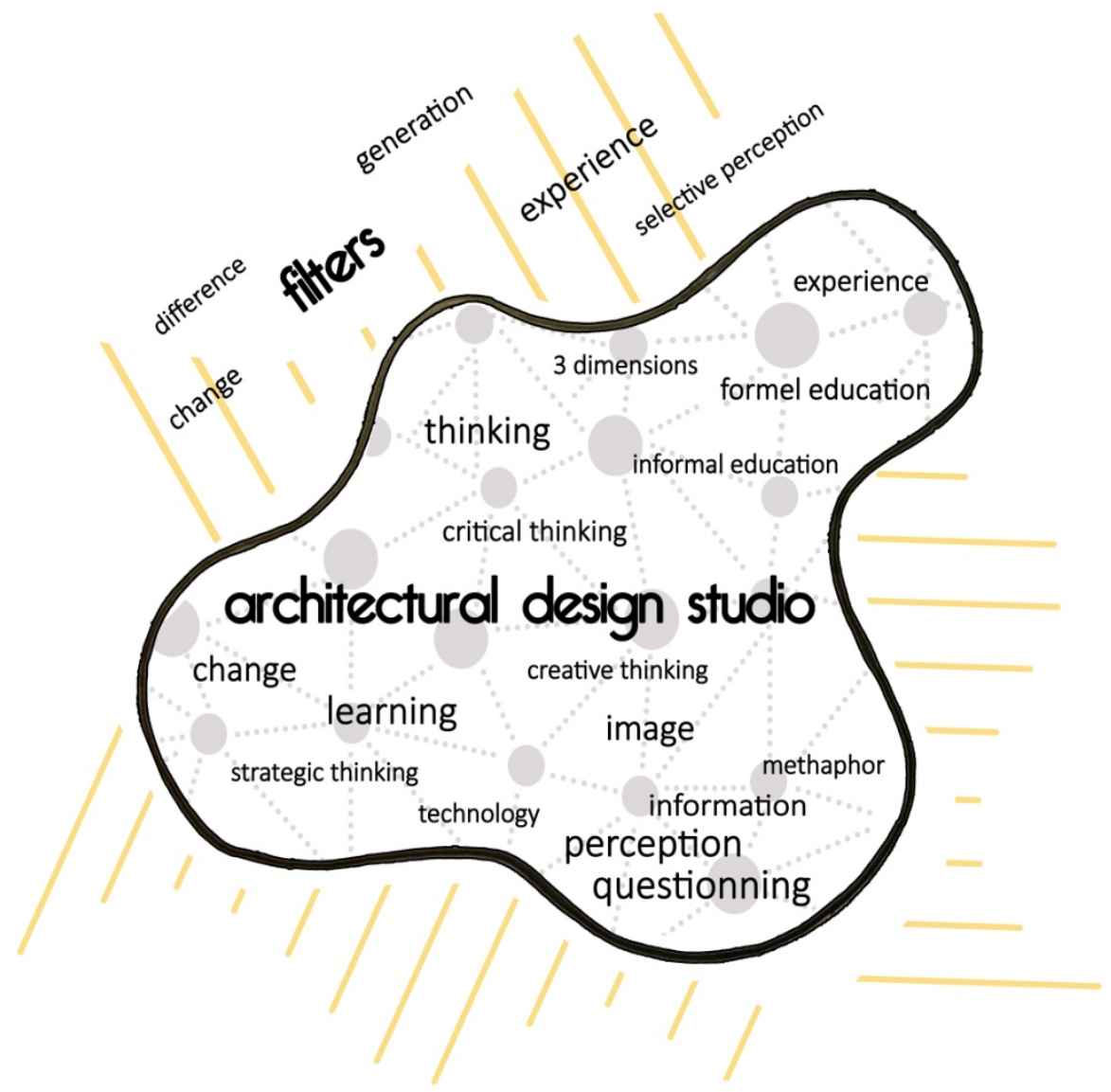

Figure 3. Diagram of studio culture (Source: Yurtsever, 2017).

\section{Discussions and Conclusions}

Briefly, decisions and selections are forming the basis of information. Each selection is added on the previous one and gives rise to the "new" one. And the knowledge of individual also differs in this direction. Experiences and consequently the perceived things and even the ones re-experienced due to that cause the creating of images peculiar to the individual. In architecture, producing genuine products may be possible by being able to see the different one and by being able to capture the different one. It may not be possible to teach it within the scope of specific rules. But for the individual to disclose the things in him/her, for him/her to gain that self-confidence and for him/her to complete the process by a specific cognition and by establishing the context shows that the learning phase is developing in a positive direction. The facts that each student has different perception levels and that the learning may be according to that are points which should not be ignored by the lecturer. As specified by Norberg-Schulz (1966), the thing that interpreted and assessed the knowledge in a manner that would assist the individual in acting properly and correctly was perception. 
In the education process of the architect, the breadth of the scope is changing on the axis of how the student can perceive the issues and make them into a whole. For this reason, the issue that needs to be addressed in education is the awareness that the student can really perceive what he sees and can actually see what he perceives. Generation of the same product should never be expected. The filters in the learning phase cause the student to have different interpretation styles. In architecture, this interpretation continues as from perception of the environment to the representation of thought. These filters add dynamism to the perception of the student. And the students understand the qualifications of the environment through dynamic interpretation process instead of understanding directly as the result of different lives. This interpretation process functions as a filter (Polatoğlu, 2012).

The filters referred by Rapoport (1977) affect the observer as well as affecting the thing seen. The important point is to enable these filters not to be lost by the student along the process of architectural education. It is being considered that the student may also realize active sharing and those more dynamic approaches through various blended approaches - which are not stable - conforming to the day's conditions, may bring in the environment the student, instructor and all their filters at the architectural design studio. The filters are components used for revealing the difference between students and the things that they have. The point required to be paid attention in the process is to be able to carry these components to a whole in a "conscious" manner. In conclusion, it can be said that being able to gain in this consciousness and sensitiveness is the education of architecture.

\section{References}

Arnheim, R. (2015). Görsel düşünme (Visual thinking). (R. Öğdül, Trans.). İstanbul: Metis Yayınları.

Berger, J. (1999). Görme biçimleri (Ways of seeing) (Y. Salman, Trans.). İstanbul: Metis Yayınları.

Brandt, R. S. (1985). Comparing approaches to thinking. In A. Costa (Ed.), Developing minds (pp. 244-246). Alexandria, V.A: Association for Supervision and Curriculum Development.

Garling, T., \& Golledge, R. C. (1989). Environmental perception and cognition. Advance in Environment, Behavior, and Design, 2(4), 203-236.

Lang, J. (Ed.). (1974). Designing for human behaviour: Architecture and the behavioral sciences. Pennysylvania: Dowden Hutchinson Ross Inc..

Lozano, E. (1988). Visual needs in urban environments and physical planning. In J. L. Nasar (Ed.), Environmental aesthetics (pp. 395-412). Cambridge: Cambridge University Press.

Lynch, K. (1996). Çevrenin imgesi (The image of the environment) (İ. Özdemir, Trans.). Cogito Yaz (Summer), 8(3), 153-163.

Norberg-Schulz, C. (1996). Intensions in architecture. Cambridge, M.A.: MIT Press.

Osguthorpe, R. T., \& Graham, C. R. (2003). Blended learning systems: Definitions and directions. Quarterly Review of Distance Education, 4(3), 227-234.

Polatoğlu, Ç. (2012). Mimarlıkta görsel etki değerlendirme yöntem ve teknikleri (Visual impact assessment methods and techniques in architecture). İstanbul: YTÜ Basım Yayın Merkezi.

Rapoport, A. (1977). Human aspects of urban form. Oxford: Pergamon Press.

Seferoğlu, S., \& Akbıyı, C. (2006). Eleştirel düşünme ve oğretimi (Teaching critical thinking). HÜ Ĕgitim Fakültesi Dergisi (Hacettepe University Journal of Education), 30, 193-200.

Yıldırım, A., \& Şimşek, H. (2008). Sosyal bilimlerde nitel araştırma teknikleri (Qualitative research techniques in social sciences). İstanbul: Seçkin Yayıncılık.

Yin, R. K. (1984). Case study research: Design and methods. USA: Sage Publications. 